\title{
FUTEBOL, POLÍTICA E IDENTIDADE: ANÁLISE DE DISCURSO DE MANIFESTOS DE MOVIMENTOS E ASSOCIAÇÕES DE TORCEDORES
}

\author{
Football, politics and identity: discourse analysis of manifestos of football fan \\ movements and associations
}
Fútbol, política e identidad: análisis del discurso de manifiestos de movimientos y asociaciones de hinchas de fútbol

Felipe Tavares Paes Lopes Professor do Programa de Pós-Graduação em Comunicação e Cultura da Universidade de Sorocaba lopesftp@gmail.com

\section{Resumo}

Este artigo tem como objetivo compreender como associações e movimentos de torcedores que surgiram após a Copa do Mundo de 2014 constroem discursivamente suas identidades em seus manifestos de fundação e de que maneiras configuram as lutas políticas no futebol. Para alcançar esse objetivo, articula as concepções de linguagem, discurso e identidade e realiza uma análise de discurso de viés construcionista. Ao fazer isso, conclui que tais identidades são respostas a fenômenos como a ascensão da extrema direita ao poder e a estigmatização das torcidas organizadas, bem como representam uma crítica ao status quo.

Palavras-chave: Futebol. Política. Identidade. Movimentos sociais. Análise de discurso.

\begin{abstract}
This article aims to understand how the football fan associations and movements that emerged after the 2014 Football World Cup discursively construct their identities in their foundation manifestos and in which ways they configure the political struggles in football. To achieve this goal, it articulates the conceptions of language, discourse and identity and conducts a constructionist discourse analysis. It concludes that such identities are responses to phenomena such as the rise of the right-wing to power and the stigmatization of organized groups of football fans, as well as they represent a critique of the status quo.
\end{abstract}

Keywords: Football. Politics. Identity. Social movements. Discourse analysis.

\section{Resumen}

Este artículo tiene como objetivo comprender cómo las asociaciones y los movimientos de hinchas de fútbol que surgieron después del mundial de 2014 construyen discursivamente sus identidades en sus manifiestos de fundación y de qué manera dan forma a las luchas políticas 
en el fútbol. Para lograr este objetivo, articula las concepciones de lenguaje, discurso e identidad y realiza un análisis del discurso construccionista. Al hacerlo, concluye que tales identidades son respuestas a fenómenos como el ascenso de la extrema derecha al poder y la estigmatización de los agrupamientos organizados de hinchas, así como representan una crítica al status quo.

Palabras clave: fútbol. Política. Identidad. Movimientos sociales. Análisis del discurso.

\section{INTRODUÇÃO}

Este artigo apresenta parte dos resultados de uma pesquisa mais ampla ${ }^{1}$ sobre o processo de construção dos problemas sociais do futebol brasileiro e, com isso, busca contribuir para o desenvolvimento dos debates travados no interior do campo de estudos sobre Comunicação e Esporte. Focalizarei, aqui, um claim-maker ${ }^{2}$ central nesse processo: os novos movimentos e associações de torcedores. Nos últimos anos, esses movimentos e associações têm recebido certa atenção do referido campo. Essa atenção é coerente com uma tradição de pesquisa, assimilada por diversas investigações desenvolvidas no âmbito dos estudos culturais (KELLNER, 2001), que optou por deslocar o olhar das grandes lutas operárias para as estratégias de resistência empregadas por diferentes grupos sociais nos mais distintos aspectos da vida cotidiana. Entre outros estudos que se debruçam sobre os referidos movimentos e associações, destacam-se os de Santos (2016; 2017) e Santos e Helal (2016), que analisaram suas lutas pelo direito ao clube e ao estádio, e os Lopes e Hollanda (2018a; 2018b), que discutiram os modos por meio dos quais eles ressignificam e contestam o processo de hipermercantilização do futebol.

A maior parte dos novos movimentos, coletivos e associações de torcedores foi fundada após a vigésima edição da Copa do Mundo de Futebol Masculino. Ocorrida no Brasil em 2014, essa edição transformou a estrutura dos principais estádios do país, convertendo-os em arenas multiusos, capazes de receber diferentes tipos de eventos em adequação a parâmetros e tendências internacionais. Esse processo de "arenização" de nossos estádios 3 modificou, por sua vez, a composição social do público, elitizando-o, devido aos altos custos repassados para os ingressos. Na Europa, a falência do grande estádio popular começou ainda na década de 1980, sendo motivada não apenas pelo risco de vida em espaços de multidão, mas, principalmente, pela emergência de uma nova economia do futebol. Nesta, as principais

\footnotetext{
${ }^{1}$ Pesquisa que possuí auxílio da Fundação de Amparo à Pesquisa do Estado de São Paulo (Fapesp).

${ }^{2}$ Construtor de problemas sociais, numa tradução livre.

${ }^{3}$ Que também alcançou alguns que ficaram de fora do mundial, como são os casos dos estádios de Palmeiras e Grêmio, que foram completamente reformulados, a fim de se adequarem ao paradigma arquitetônico denominado "padrão FIFA".
} 
fontes de receita dos clubes passaram a ser não mais afluência maciça de pessoas com baixo poder aquisitivo aos estádios, mas os opulentos contratos de patrocínio e de transmissão televisiva. Foi aí que atletas passaram a ser extremamente valorizados, assinando contratos astronômicos - o que acabou despertando na classe-média e elite o interesse de pagar caro para assistir a uma partida de futebol, desde houvesse condições de conforto e segurança. No Brasil, o processo de "arenização" começou a ganhar forma na década de 1990, com destaque para a construção da Arena da Baixada. Esse processo fortaleceu-se anos mais tarde, com o fim definitivo das "gerais" do Maracanã e do Beira Rio. Mas foi mesmo com a Copa de 2014, que visava promover uma "boa imagem" da nação e tornar o Brasil "competitivo" no circuito mundial da "mercadoria-turismo", que ele foi radicalizado (MASCARENHAS, 2014).

O processo de "arenização" dos estádios impactou a experiência de torcer, tornando-a mais distanciada e passiva, devido à imposição de uma série de elementos que restringe a formação de massas compactas e fervilhantes - tais como a criação de áreas exclusivas e o encadeiramente de todos (ou praticamente todos) os setores (LOPES; HOLLANDA, 2018a). No plano jurídico, o Estado de Defesa do Torcedor, implementado em 2013, já previa uma série de punições para transgressores e o aumento panóptico do controle dos frequentadores de estádio. No entanto, de acordo com Mascarenhas (2014, p. 2018), com a Copa de 2014, houve um recrudescimento inédito desse controle, “[...] anulando a criatividade coletiva e reduzindo ao mínimo a possibilidade de expressão individual”. Essa anulação, aliada à nova composição social dos frequentadores, conformou uma nova territorialidade torcedora, fortemente excludente - que estimulou o surgimento de diversos coletivos, movimentos e associações de torcedores que visavam (e ainda visam) se contrapor a esse novo cenário, ainda que com pautas diversas.

Além de radicalizar o processo de "arenização", a Copa de 2014 - e, também, os Jogos Olímpicos de 2016 - foi marcada por escândalos de corrupção e por projetos políticos e de intervenção urbana que foram objeto de forte contestação por parte de vários atores sociais, como movimentos sociais. Entre outras coisas, esses movimentos criticaram o caráter autoritário desses projetos, alimentado por decretos, regras e leis excepcionais, como, por exemplo, a Lei 12.663/2012 (mais conhecida como Lei Geral da Copa), que estabeleceu exceções à ordem jurídica vigente para algumas situações especiais relacionadas à Copa de 2014 e à Copa das Confederações de 2013 (OLIVEIRA, VAINER, 2014). Também foram amplamente criticadas as remoções e as diversas desapropriações realizadas para a realização desses megaeventos. Ao abordar o caso do Rio de Janeiro, Nacif e Faulhaber (2014) 
observam que elas ocorreram nas áreas mais valorizadas da cidade ou com potencial para valorização após a realização das intervenções. Em outras palavras, foram realizadas para atender aos interesses do mercado imobiliário.

Outro fator que contribuiu para o surgimento dos novos coletivos, movimentos e associações de torcedores foi o processo global de organização e politização dos frequentadores de estádios. De acordo com Numerato (2014), esse processo teve início após a Segunda Guerra Mundial - quando, no Reino Unido, começou a se desenvolver uma cultura de contestação torcedora, que fazia frente ao aumento da profissionalização do mercado de transferência e ao aburguesamento do futebol. No entanto, segundo o autor, foi somente em meados da década de 1980 que essa cultura se tornou mais explícita, graças ao surgimento de uma série de associações independentes de torcedores ${ }^{4}$. Na década de 1990, após a elaboração do famoso Relatório Taylor, que modificou a configuração dos estádios britânicos, a Associação Nacional dos Torcedores (FSA) tornou-se uma das principais vozes dos torcedores contra alguns dos efeitos negativos dessa modificação. Em outros lugares da Europa, como a Alemanha, os grupos ultras, designação italiana dos anos 1960 e 1970, representam a principal subcultura de torcedores e, há décadas, realizam protestos e manifestações contra a hipermercantilização do futebol.

Com a rápida evolução da internet e o advento de novas formas de comunicação móveis e em rede, essa cultura de contestação acabou repercutindo no Brasil, inspirando e influenciando a formação de novos movimentos de torcedores. Cabe destacar, todavia, que essa cultura já ressoava nos estádios brasileiros desde a segunda metade dos anos 1960, quando surgiram as primeiras torcidas organizadas. Afinal, tais torcidas nasceram reivindicando autonomia face aos clubes e adotando um novo estilo de torcer, a fim de demarcar distinção em relação às charangas e aos outros agrupamentos de torcedores da época. Ademais, ao longo das décadas, criaram uma série de entidades representativas, a fim de lutar pelos direitos dos torcedores. Hoje em dia, a principal delas é a Associação Nacional das Torcidas Organizadas do Brasil (Anatorg). Esta foi sendo sedimentada nos diversos seminários regionais e nacionais organizados pelo Ministério do Esporte durante as gestões petistas. Também foi importante para sua sedimentação um intercâmbio realizado na Alemanha, em 2014, que contou com uma comitiva constituída por autoridades públicas, professores/pesquisadores e lideranças de torcidas organizadas. Afinal, esse intercâmbio

\footnotetext{
${ }^{4}$ Segundo Giulianotti (2002), os fanzines foram um canal crucial para essas associações manifestarem seus pontos de vista e demonstrar aos políticos que a maioria dos torcedores não era constituída por hooligans.
} 
permitiu que tais lideranças estabelecessem contato com as principais lideranças ultras da Alemanha e conhecessem os projetos socio-pedagógicos realizados com os torcedores considerados mais "radicais" (TEIXEIRA; LOPES, 2018).

Um fator externo ao universo do futebol que contribui para a aparição dos novos movimentos, coletivos e associações de torcedores foi a ascensão da extrema direita no Brasil. De acordo com Löwy (2015), assim como a europeia, a extrema direita brasileira cultua a violência policial, é extremamente intolerante com as minorias sexuais - em particular os homossexuais - e tem, com certa eficácia, manipulado demagogicamente o tema da luta contra a corrupção. Todavia, segue o autor, ela também apresenta algumas particularidades. Em primeiro lugar, não existe no Brasil um partido de massa que tenha o racismo como sua principal bandeira - o que não significa que nosso país seja uma "democracia racial”, apenas que o racismo está presente de forma mais difusa na nossa sociedade. Em segundo lugar, a maior parte dos grupos de extrema direita brasileiros reivindica a implementação de uma ditadura militar, aos moldes da ocorrida de 1964 a 1985. Em terceiro lugar, esses grupos não possuem, de uma forma geral, uma relação de continuidade política e ideológica com os movimentos fascistas clássicos - como, por exemplo, o integralismo, que chegou a ter bastante força nos anos 1930, a ponto de ter influenciado o golpe que levou à constituição do Estado Novo (1937-1946) ${ }^{5}$.

Sendo assim, podemos dizer que a atual extrema direita brasileira constituí, sob vários aspectos, um fenômeno recente. Não à toa, fala-se em "nova direita brasileira". Esta, todavia, não compõe um bloco homogêneo, mas, sim, um campo de disputas, marcado por fissuras e conflitos. Ainda que a formação desse campo não tenha se dado de uma hora para outra, é possível destacar alguns marcos importantes. Segundo Brugnago e Chaia (2015), as passeatas ocorridas em junho de 2013, que ficaram conhecidas como "Jornadas de Junho", fizeram reflorir a identificação das pessoas entre esquerda e direita, produzindo um novo capítulo na história da participação política brasileira. Embora tenham sido inicialmente organizadas por um grupo da vanguarda estudantil, o Movimento Passe Livre (MPL), que lutava contra o aumento das passagens de ônibus na cidade de São Paulo, logo essas passeatas ganharam uma dimensão nacional e a referida luta deu lugar a diversas outras demandas, criando uma agenda multifacetada. Ao mesmo tempo, ações de natureza fascista começaram a ganhar as ruas, como a perseguição a bandeiras e símbolos de sindicatos e partidos políticos de esquerda. É

\footnotetext{
${ }^{5}$ Aqui, vale salientar que ainda existem grupos integralistas, mas pouco expressivos.
} 
importante observar aqui que, se a militância de esquerda já estava acostumada a protestar, sair às ruas foi uma grande novidade para a nova militância de direita.

A partir das Jornadas, criou-se, então, uma profunda polarização político-ideológica na sociedade brasileira. De acordo com Brugnago e Chaia (2015), essa polarização não se deu, todavia, de forma simétrica. Afinal, se a esquerda, por um lado, passou a agrupar movimentos mais moderados, que não pregavam necessariamente a defesa de um regime socialista; a direita, por outro, radicalizou seu conservadorismo e discurso de ódio à esquerda e ao Partido dos Trabalhadores (PT), em particular. Esse discurso acirrou-se nas eleições presidências de 2014, que tiveram um elemento novo: o amplo uso de redes sociais virtuais, como o Facebook. Tais redes contribuíram para a produção de novos conflitos e para a difusão de notícias falsas. Em 2014, também surgiram uma série de movimentos de rua de direita, como o Movimento Brasil Livre (MBL) e o Vem pra Rua, que logo se tornaram protagonistas nas manifestações a favor do impeachment da então presidenta da República Dilma Rousseff, que se concretizou em 2016. Dois anos depois, com a população brasileira bastante dividida, Jair Bolsonaro elegeu-se presidente da República, com uma agenda econômica ultraliberal, uma pauta fortemente conservadora no campo dos costumes e um discurso altamente agressivo, que expurgava a esquerda e grupos subalternos, como o movimento LGBTQ+.

Paralelamente, o "campo progressista" começou a reagir. Primeiramente, organizando campanhas e manifestações contra o então presidente Michel Temer (“Fora, Temer!”) e sua reforma trabalhista, que propunha a subtração de uma série de direitos dos trabalhadores. E, em seguida, realizando passeatas contra o então candidato Bolsonaro (“Ele não!”) e sua agenda política de extrema direita. Essa reação alcançou o universo do futebol, fazendo emergir ou fortalecendo coletivos de torcedores de esquerda e antifascistas. Além de enfrentar o processo de "arenização" dos estádios, esses coletivos passaram a construir uma agenda em torno de preocupações comuns, como a homofobia, o sexismo, o racismo e outras formas de intolerância e exclusão no futebol brasileiro. Temas que, muitas vezes, permanecem na penumbra, não ganhando destaque na agenda de outros claims-makers, como os meios de comunicação (LOPES, 2019).

De acordo com Lopes e Hollanda (2018b), os novos coletivos, movimentos e associações de torcedores engajam-se, com frequência, em uma série de atividades (seminários, protestos, reuniões etc.) voltadas ao enfrentamento dessas formas de intolerância e exclusão, bem como de outras condições do futebol brasileiro e da sociedade em geral que são por eles classificadas e avaliadas como problemáticas. Mas quem são exatamente esses 
grupos? Ao levantar essa questão, não pretendo, neste texto, verificar se enquadram-se nesta ou naquela definição de movimentos sociais, de acordo com este ou com aquele autor. Mas, sim, examinar como definem a si mesmos. Mais exatamente, meu objetivo aqui é compreender como associações e movimentos de torcedores que surgiram após a Copa do Mundo de 2014 constroem discursivamente suas identidades em seus manifestos de fundação e de que maneiras configuram as lutas políticas no futebol. Para alcançar esse objetivo, abordo dois deles: a Anatorg e o movimento Arquibancada, Ampla, Geral e Irrestrita (AGIR), que agrega uma série de coletivos de torcedores de esquerda. Antes de abordá-los de modo mais aprofundado, apresento, todavia, o referencial teórico que orientou as análises aqui apresentadas.

\section{LINGUAGEM E IDENTIDADE SOCIAL: A PERSPECTIVA CONSTRUCIONISTA}

Este trabalho segue os caminhos abertos e trilhados por autoras e autores filiados ao construcionismo, tais como Iñiguez (2001; 2002) e Ibañez (2001). Embora essa perspectiva não deva ser entendida como um referencial teórico homogêneo, uma vez há diferenças internas importantes ${ }^{6}$, considero que, de modo geral, ela se preocupa com o processo por meio do qual descrevemos e explicamos o mundo, incluindo nós mesmos (GERGEN; GERGEN, 2011). Como retomarei, tais descrições e explicações não devem ser entendidas como expressões daquilo que acontece "dentro" da nossa mente, mas como formas de ação. Afinal, o construcionismo posiciona-se contra o realismo fundante da retórica da ciência na modernidade, criticando suas ideias centrais, como “[...] a dualidade sujeito-objeto, a concepção representacionista do conhecimento, a retórica da verdade e o cérebro como instância produtora do conhecimento" (SPINK; FREZZA, 1999, p. 27).

De acordo com Gergen e Gergen (2011), o construcionismo parte de uma ideia simples, porém profunda: nada é real até que entremos em acordo do que é, ou seja, a realidade deve ser concebida como o produto de nossas convenções. Vale ressaltar que essa ideia não conduz a perspectiva construcionista ao solipsismo, como poderíamos supor num primeiro momento. Afinal, ela estabelece uma diferença, crucial para seu entendimento, entre os discursos sobre o ser e sobre a realidade. O discurso sobre esta última tem como objeto um determinado modo de ser, e não o ser em si. Com isso, o construcionismo reconhece que há algo com total independência daquilo que podemos individualmente pensar, dizer e desejar.

\footnotetext{
${ }^{6}$ Podemos dizer, por exemplo, que há versões mais fracas e mais fortes do construcionismo, dependendo do tipo de ontologia assumida (mais ou menos relativista) (SPINK; FREZZA, 1999).
} 
Em outras palavras, não nega a existência do ser, mas argumenta que suas formas, conteúdos, estruturas e características dependem completamente de nós - sujeitos históricos, sociais, culturais e biologicamente determinados (IBAÑEZ, 2001; 2005).

Com efeito, se a realidade depende necessariamente de nós, então somos levados a crer que não pode ser acessada em si mesma, ou seja, o mundo social só pode ser entendido a partir da perspectiva de um observador, que está invariavelmente inserido em uma tradição cultural. Sendo assim, a construção da realidade depende do uso de algum tipo de linguagem. Esta, vale salientar, é parte da sociedade; não algo externo a ela. Afinal, ao mesmo tempo em que é moldada por um conjunto de regras, é uma prática constituinte e reguladora (IÑIGUEZ, 2002). Diante disso, não deve ser entendida de forma cartesiana, ou seja, como uma roupagem que serve para vestir nossas ideias e apresentá-las ao exterior, tornando-as visíveis para o outro. Não se trata, portanto, de um meio transparente entre uma pessoa e o mundo. De uma forma neutra de manifestar um estado mental. Ao contrário, é condição do próprio pensamento. Mas a linguagem não se limita a fabricar ideias; ela fabrica, também, outras realidades, podendo ser interpretada como um instrumento ativo na produção dos mais variados fenômenos (IBAÑEZ, 2004). Em suma, ela não só nos diz como mundo é, mas também o institui.

Neste contexto, a identidade das pessoas não deve ser entendida como determinada ou guiada por um substrato natural-biológico. Tampouco deve ser colocada em um (suposto) "mundo interior", que seria a causa dos comportamentos e experiências das pessoas. Mas deve ser vista como um produto da linguagem (IÑIGUEZ, 2002). Esta não é apenas constitutiva das identidades individuais, mas também das sociais, isto é, daquelas que derivam do nosso pertencimento a um grupo social (REICHER; HOPKINS; LEVINE; RATH, 2005). Afinal, a linguagem é a ferramenta por meio da qual formamos a "imagem" de um grupo, ou seja, daquilo que unifica seus membros e daquilo que os separa dos demais. Essa "imagem", todavia, é objeto de frequentes negociações. Não se trata de algo estático, mas de algo que surge no transcorrer de interações sociais concretas. Nesse sentido, podemos dizer que o construcionismo dessencializa a noção de identidade social, chamando a atenção para o fato de as identidades não preexistirem às relações que as constituem, inserindo-as no coração da história e da sociedade. Para tal perspectiva, a maneira como experimentamos ser parte de um grupo não é, portanto, universal, mas está sujeita a variabilidades interculturais (IÑIGUEZ, 2001). 


\section{MÉTODO E PROCEDIMENTOS}

Entendendo que nenhum método tem status próprio, mas precisa ser definido e delimitado dentro de um quadro teórico de referência, busquei realizar uma análise de discurso coerente com a perspectiva construcionista. Assim, seguindo sua concepção de linguagem, considero que todo discurso deve ser concebido como uma prática linguística, com traços característicos e consequências práticas, podendo, portanto, impactar as relações sociais. Desse ponto de vista, analisar um discurso significa estudar como as referidas práticas atuam, no presente, mantendo ou promovendo essas relações (IÑIGUEZ, 2002).

\subsection{Construção do corpus}

A fim de levar a cabo tal análise, selecionei, conforme já foi antecipado, duas instituições para examinar como suas identidades são discursivamente construídas: a Anatorg e o AGIR. Sua escolha deve-se ao fato de serem as maiores e mais representativas entidades de torcedores do pós-Copa do Mundo de 2014. A Anatorg é, hoje em dia, a principal associação representativa de torcidas organizadas no país. Fundada oficialmente em dezembro de 2014, em um seminário organizado pelo Ministério do Esporte, ela foi o resultado de um pacto de 103 agrupamentos e constitui um marco na história do associativismo torcedor no Brasil (TEIXEIRA; LOPES, 2018). Por sua vez, o AGIR reúne 27 coletivos e movimentos de torcedores de diferentes clubes e correntes de esquerda. Fundado oficialmente em outubro de 2016, na Faculdade de Filosofia, Letras e Ciências Humanas da Universidade de São Paulo, o movimento defende pautas progressistas no futebol e na sociedade em geral e posiciona-se contra os considerados retrocessos sociais e políticos em curso no Brasil após o impeachment de Dilma Rousseff (LOPES; HOLLANDA, 2018a; 2018b).

Uma vez selecionadas as instituições a serem investigadas, defini o material discursivo a ser examinado: manifestos da Anatorg e do AGIR. A opção por trabalhar com esse material justifica-se pelo fato de ele ser representativo dos discursos dessas instituições. Afinal, conforme Iñiguez (2002), em análise de discurso, o termo representatividade não deve assumir seu significado estatístico, ou seja, não importa se o participante é estatisticamente representativo da população em consideração: se está perto da sua média etária, socioeconômica, cultural etc. Mas, sim, se atua como se estivesse no papel de membro dessa população, independentemente de suas qualidades individuais - como é, evidentemente, o caso do autor de um manifesto de uma associação. 
A fim de obter o referido material, entrei nas páginas oficiais da Anatorg e do AGIR no Facebook. Afinal, devido ao meu conhecimento prévio dessas instituições, obtido em investigações anteriores, sabia que essa rede social virtual era (e ainda é) um meio de comunicação muito utilizado por elas ${ }^{7}$. Ademais, essas páginas foram criadas pouco antes de as associações serem oficialmente fundadas ${ }^{8}$ - o que me permitiria (e permitiu) acessar os seus primeiros manifestos. Vale salientar aqui que, a despeito de fornecer um rico material para investigação, tais páginas não foram analisadas em sua totalidade. Em outras palavras, não busquei analisar o leque de representações presentes nas mais diversas postagens, ou quantificar seus compartilhamentos ou, ainda, investigar o conteúdo e a dinâmica dos comentários. Tampouco busquei interagir com outros usuários. O Facebook foi, portanto, apenas um meio para acessar um material previamente definido.

Uma vez definido esse meio, li todos os posts das páginas do Facebook de ambas instituições, a fim de identificar os manifestos por elas assinados e publicados desde sua origem e os salvei no computador em arquivo Word, para facilitar seu posterior manuseio. Encontrei cinco manifestos, sendo quatro assinados pela Anatorg e um, pelo Agir. Feito isto, li repetida e atentamente os textos selecionados na íntegra e optei por focalizar os manifestos de fundação dessas instituições (um de cada), uma vez que tratavam mais diretamente da questão identitária. Como qualquer manifesto, os selecionados constituem uma declaração trazida a público, com o objetivo, no caso, de apresentar as próprias instituições, bem como suas condições de produção.

\subsection{Tratamento e análise do corpus}

Para analisar os manifestos de fundação, adotei, fundamentalmente, duas estratégias, que se sobrepõem e se reforçam mutuamente: primeira, examinei como a Anatorg e o AGIR nomeiam e caracterizam a si mesmos, bem como quais ações atribuem a si (ROJO, 2002). Conforme antecipei, da perspectiva construcionista, a identidade de um indivíduo ou de um grupo social é constituída, essencialmente, por meio da linguagem. Assim, esse processo de nomeação, caracterização e atribuição de ação não deve ser entendido aqui como um processo de etiquetagem de uma referência preexistente. Se assim fosse, teríamos de aceitar a existência de uma realidade pré-simbólica, independentemente de um observador - o que seria contraditório com a referida perspectiva. $\mathrm{Na}$ verdade, seguindo seus princípios, entendo

\footnotetext{
${ }^{7}$ Apenas para dimensionar o alcance das páginas, em 08 de maio de 2020, a primeira possuía 20.428 seguidores e a segunda, 1.951.

${ }^{8}$ A página da Anatorg foi criada em 5 de setembro de 2014 e a do AGIR, em 10 de outubro de 2016.
} 
que tal processo efetivamente dá existência a um ser e, por esta razão, merece ser analisado. Apenas para dar um exemplo: utilizar as palavras "imigrante" ou "cidadão" para nomear uma pessoa que passou a viver no Brasil não é apenas uma forma distinta de representá-la, mas contribui para construí-la (ou não) como parte da "nossa" sociedade. Enquanto o primeiro termo é uma forma de designação que separa, que marca uma nítida diferença entre um "nósbrasileiros" e um "ele" que irrompe o "nosso" território; o segundo é uma forma de designação que une, que apaga a fronteira entre esse "nós" e esse "ele", fazendo deste último um sujeito merecedor dos mesmos direitos do que "nós".

Segunda, examinei como os discursos veiculados nos manifestos são moldados por outros textos, aos quais procuram "responder" ou se "antecipar", ou seja, examinei-os à luz da noção de intertextualidade (FAIRCLOUGH, 2008). De acordo com Potter (1998), essa noção foi desenvolvida por Julia Kristeva a partir da noção de heteroglossia9 ${ }^{9}$, de Mikhail Bakhtin, e permite-nos estabelecer relações, frequentemente ocultas, entre textos, discursos e gêneros ${ }^{10}$. Tal conceito é especialmente relevante para este trabalho pois contribui para acentuar o caráter social e historicamente construído das identidades, afinal mostra como assimilam, ecoam e/ou contradizem textos prévios.

Ao focalizar as duas estratégias supramencionadas, deixei, evidentemente, de analisar diversos aspectos dos textos relevantes para uma análise de discurso mais completa. No entanto, como ocorre em qualquer análise, foi preciso fazer escolhas e efetuar recortes.

\footnotetext{
${ }^{9}$ Grosso modo, esta chama a atenção para as múltiplas vozes da linguagem, ou seja, para o fato de que o discurso do narrador é sempre o de outro.

10 Fairclough (2008) distingui a intertextualidade em dois tipos: a manifesta, em que um texto recorre explicitamente a outro, e a constitutiva, também por ele denominada de interdiscursividade. Esta última estende a intertextualidade à primazia da ordem do discurso, ou seja, à "[...] totalidade de práticas discursivas dentro de uma instituição ou sociedade, e o relacionamento entre elas" (p. 67). Ainda que essa distinção possa ser útil analiticamente, a fim de não deixar o texto demasiadamente técnico e pouco fluído, falarei aqui apenas em "intertextualidade" para ambos os casos.
} 


\section{RESULTADOS}

A apresentação dos resultados da análise foi dividida por manifesto. Começo pelo do Agir.

\subsection{Análise do manifesto do AGIR}

O manifesto do AGIR é assinado por 27 movimentos e coletivos de torcedores ${ }^{11}$. De partida, define o movimento por meio do emprego do pronome de primeira pessoal no plural "nós", delimitando uma fronteira entre o exogrupo (grupo de fora) e o endogrupo (grupo de dentro). Este seria composto por "torcedoras e torcedores de diversos clubes, militantes de esquerda, integrantes de coletivos de naturezas diversas, estudiosas e estudiosos, além de profissionais ligados ao esporte". Ao descrever-se dessa forma, o AGIR, em primeiro lugar, constrói a si mesmo como uma instituição plural, que abriga diferentes grupos sociais, ainda que a caracterização de um deles como sendo de esquerda (o de militantes) tenda, por extensão de sentido, a fazer crer que essa qualidade seja um elemento unificador do grupo. Caso contrário, também haveria militantes de direita. Em segundo lugar, constrói-se como não sexista por meio do uso de uma linguagem inclusiva, que reforça seu caráter progressista. Notemos que, no caso dos coletivos não-neutros, o manifesto utiliza as duas formas no plural, flexionando primeiro o feminino (“torcedoras e torcedores", por exemplo).

Em seguida, o manifesto constrói o AGIR como uma resposta à "pauta conservadora que possibilitou a instauração do governo ilegítimo de Michel Temer”. Aqui, ele faz eco ao discurso de parte significativa da esquerda de que o impeachment de Dilma Rousseff foi um "golpe", situando-se ao lado dessa parte, o que é reforçado na sentença seguinte: "decidimos somar forças com os demais movimentos sociais na luta contra o retrocesso político." $\mathrm{O}$ primeiro ponto importante a ser examinado aqui é o pressuposto do trecho "demais movimentos sociais": o de que ele próprio é um movimento social. Essa não é uma concepção qualquer, mas carregada de significado dentro do contexto das Ciências Humanas e Sociais. Trata-se, na verdade, de uma categoria polissêmica, que possui uma longa história de disputas em torno de seu significado. Ainda que o manifesto deixe esse significado em aberto, não

\footnotetext{
11 Os grupos que assinaram o manifesto foram: Ação Antifascista, Boxe Autônomo, Celeste Proletária FLC, Coletivo Democracia Corintiana, Comuna Rubro-Negra, Dá Bola Pra Elas, Dibradoras, Esquerda Alvinegra, Futebol, Mídia e Democracia, Inter Antifascista, LEFTe - Laboratórios de Estudos sobre Futebol e Esporte, Galo Marx, Ludopédio, Movimento 20 de Setembro, Movimento Punk Santista, P16 - Palmeiras Antifascista, Palmeiras Livre, Pelado Real FC, Porcomunas, Rede Brasileira de Futebol e Cultura, Rede Paulista de Futebol de Rua, Resistência Azul Popular, Respeito Futebol Clube, Santos Antifascista, São Paulo Antifascista, Teóricos do Futebol, Tricolor Socialista.
} 
especificando o que entende exatamente por movimento social, o uso de tal categoria tende a revestir o AGIR com a imagem da militância política. Não se trata de um agrupamento qualquer, mas organizado e atuante politicamente. Mais adiante, todavia, o complemento "social" é subtraído e o manifesto define o AGIR apenas como um "movimento" - o que, de certa forma, retira do agrupamento o "peso" de autodefinir-se como um movimento social e, consequentemente, evita comparações com os objetivos e modos de operação de movimentos sociais tradicionais, como o Movimento dos Sem Terra (MST).

Vale ressaltar também o uso da expressão "somar forças", que confere um sentido positivo ao AGIR. Afinal, ele não seria um grupo que fragmenta, segrega, mas destinado a atuar ao lado daqueles que podem se constituir em um desafio real a um "retrocesso político". Esse sentido é reforçado no momento seguinte do manifesto, que constrói o AGIR como uma instituição propositiva, que "apresenta questões", a fim de "estimular o debate" e atuar contra a "articulação reacionária", conforme indica o extrato abaixo.

Com esse intuito, além das bandeiras já empunhadas por outros agrupamentos, apresentamos questões específicas referentes aos esportes em geral e ao futebol em particular. Pretendemos com isso, estimular o debate sobre as relações entre política e esporte e atuar nos espaços públicos contra a articulação reacionária que se instaurou no Brasil.

Por fim, o manifesto termina fazendo um convite para que todas e todos que compartilhem suas perspectivas envolvam-se na criação do movimento, bem como apresenta sua pauta inicial, que envolve não apenas questões diretamente relacionadas ao futebol, mas, também, ao contexto político e social mais amplo, como a oposição à reforma do ensino médio e à pauta, classificada como "conservadora", do então presidente Michel Temer.

Convidamos todas e todos que compartilhem dessas perspectivas a se envolverem no processo de criação do movimento Arquibancada: Ampla, Geral e Irrestrita (AGIR), que tem como pauta inicial os seguintes pontos:

1. Contra o golpe parlamentar: Fora Temer.

2. Contra a pauta conservadora do governo Temer e do atual Congresso.

3. Nenhum direito a menos: nas ruas e nas arquibancadas.

4. Pela democratização e participação popular nos clubes e federações e nos espaços de elaboração de leis e politicas públicas para o esporte. Fora Marco Polo Del Nero.

5. Dá a bola pra Elas!

6. Festa popular na arquibancada!

7. Esporte para todas e todos: pela criação de um Sistema Nacional de Esporte

8. Por políticas públicas que incentivem as práticas esportivas de mulheres e da comunidade LGBT.

9. Pela democratização das cotas de transmissão e o fortalecimento do 


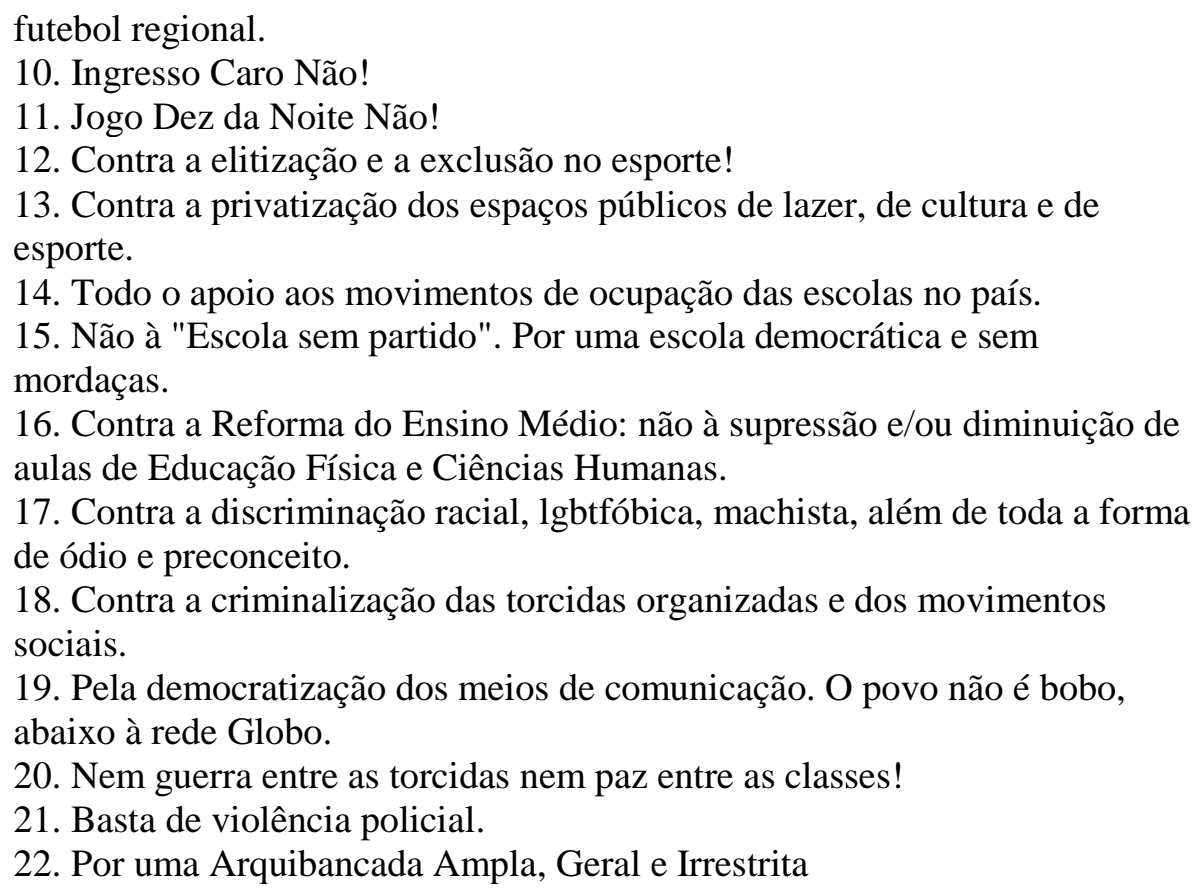

Ainda que a análise das 22 questões apontadas no manifesto escape dos estreitos limites deste trabalho, cabe destacar que essas questões contribuem, primeiro, para construir o movimento como multifocal, que atua em diversas áreas, e não apenas no universo do futebol. Segundo, para construí-lo como de esquerda, dado que elas facilmente poderiam ser inseridas em uma agenda dita progressista. Em relação a este último ponto, uma análise intertextual é bastante sugestiva. Tomemos como exemplo as questões 20 ("Nem guerra entre as torcidas nem paz entre as classes!") e 22 ("Por uma Arquibancada Ampla, Geral e Irrestrita"). A primeira é o lema da torcida Ultras Resistência Coral, do Ferroviário Atlético Clube, do Ceará $^{12}$. Lema que, por sua vez, faz alusão à palavra de ordem dos bolcheviques diante dos conflitos na Primeira Grande Guerra: "Nem guerra entre os povos nem guerra entre as classes”. Já a segunda questão alude às lutas travadas no fim da ditadura civil-militar (19641985) pela anistia aos presos e perseguidos políticos. Lutas que tinham como palavra de ordem "por uma anistia ampla, geral e irrestrita".

\subsection{Análise do manifesto da ANATORG}

O manifestado da ANATORG é assinado pelo seu então presidente, André Azevedo, e, diferentemente do manifesto do AGIR, começa pela definição daquilo que a associação não é. Ou melhor, daquilo que não são seus representados: as torcidas organizadas. Para tanto,

12 Torcida fundada em 2005 por anarquistas e comunistas. 
evoca a fala do senso-comum, suas ideias-feitas, isto é, aquelas ideias que todo mundo faz dessas torcidas. Ideias que, de acordo com Bourdieu (1997), são banais, convencionais, comuns. Que todos tendem a admiti-las instantaneamente. Afirma o manifesto:

quando falamos de torcidas organizadas, a primeira coisa que nos vem a cabeça infelizmente é violência, mortes, marginais, desocupados e outros adjetivos. Ao menos é isso que todos querem induzir a pensar. Festas, ações sociais, consciência social, carnaval e outros tipos de ações positivas soam como um nada na casa de todo cidadão.

De partida, o advérbio "infelizmente" contrapõe a visão do autor à do senso-comum, sugerindo que ele a lamenta, valorando-a negativamente. Em seguida, indica que essa segunda visão é incitada de forma persuasiva, mas que não, necessariamente, efetiva-se na prática. Notemos o uso do verbo "querer", que está no plano do desejo, da intenção. Depois, o manifesto fortalece a referida contraposição descrevendo uma série de práticas (socialmente classificadas como positivas) que são levadas a cabo pelas organizadas, mas que ficam na penumbra. Que, nas suas palavras, "soam como um nada".

Dito isto, o manifesto afirma o seguinte:

temos hoje um segmento social com quase dois milhões de pessoas (sem contar o alcance indireto) e fico apenas pensando onde as pessoas entendem que nessa quantidade de gente teríamos um comportamento diferente da nossa sociedade brasileira, onde convivemos com violência no nosso dia a dia e em todas as esferas extra-futebol.

Vale ressaltar, aqui, o uso de números para descrever o movimento de torcidas organizadas. A Anatorg alcançaria diretamente (ou seja, no mínimo) quase dois milhões de pessoas. Independentemente de como se tenha calculado esse número, é importante destacar aqui que ele possui uma função persuasiva. Explico: geralmente, entende-se que os números são maneiras objetivas e neutras de captar a realidade, passando por alto seu caráter construtivo e retórico (POTTER, 1998). No entanto, de acordo com Best (2003), eles são, na verdade, o produto de uma ação humana. De uma construção efetuado pelo próprio pesquisador. Afinal, é este que escolhe a amostra (o que contar) e o método (como contar). Toda conta pressupõe, por conseguinte, uma série de convenções, sem as quais não seria possível ser realizada. Convenções que tanto contribuem para maximizar quanto para minimizar algum "aspecto da realidade". Nesse sentido, podemos dizer que efetuam uma "manipulação ontológica" (POTTER, 1998), a fim de legitimar ou deslegitimar alguma ação 
ou ideia. No caso, atacar a voz do senso-comum e defender a própria instituição. Afinal, o referido número é a base do seguinte silogismo: as torcidas organizadas constituem um enorme segmento social. Logo, representativo da sociedade. A sociedade convive com a violência. Logo, a Anatorg também.

Seguindo com a análise intertextual, no trecho subsequente, o autor evoca mais explicitamente a voz do senso-comum por meio do verbo "escutar". Em seguida, evoca sua própria voz - que se funde com a da Anatorg, por meio da primeira pessoa do plural "nós dizemos" - para rebater a primeira voz. Para tanto, faz ecoar a perspectiva que Umberto Eco (1979) denominou de apocalíptica, que vê a comunicação de massa como um poderoso instrumento de alienação. De "manipulação", para utilizar as palavras empregadas no manifesto. A televisão, segundo o documento, ocultaria uma série de problemas no futebol, bem como suas fontes, fazendo das organizadas os "bodes expiatórios". Em outras palavras, aqui, o manifesto posiciona as organizadas como vítimas da mídia, o que contribui para produzir um sentimento no leitor de simpatia por elas. Ao mesmo tempo, ao observar que a sociedade compraria a referida versão das organizadas por "falta de conhecimento", reforça sua condição de alienada, aludindo novamente à "perspectiva apocalíptica".

Escutamos que as pessoas não vão mais aos estádios devido à violência e para essas pessoas nós dizemos: por favor, não vá mais à praia no domingo e nem a bares à noite, pois lá também está constatado que é tão ou mais perigoso do que ir ao futebol. Vemos rankings da televisão colocando que o principal motivo da ausência do torcedor é a violência nos estádios, mas alguém saberia nos dizer qual seria o segundo motivo? Não! A razão todos sabem: é uma coisa manipulada, em que não querem que se abram discussões sobre valores de ingressos, horários de jogos, falta de transporte, corrupção dos engravatados de confederações e dirigentes de clubes. Ou seja, são fontes intermináveis de problemas no futebol, mas o bode expiatório de tudo isso somos nós, os torcedores organizados. E por falta de conhecimento a sociedade compra essa ideia.

No momento subsequente, o manifesto segue trazendo argumentos contrários à ideia de que o principal problema do futebol seja a violência e posiciona, novamente, as organizadas como vítimas - "somos usados e marginalizados" -, sem, desta vez, especificar o “vilão". Esse processo de vitimização serve, depois, para legitimar a própria criação da Anatorg. Tal processo envolve uma estratégia complexa: num primeiro momento, o autor funde sua voz com a dos próprios torcedores organizados - "nós os torcedores organizados" para, em seguida, interpretar a própria coletividade por meio da chave de leitura da alienação. Notemos o uso do verbo "acordar", que pressupõe que os referidos torcedores estavam 
adormecidos, sedados. Em seguida, o autor faz uma ameaça - "tenham medo sim" - sem mencionar diretamente o ameaçado. Todavia, somos levados a crer que se tratam dos "inimigos" das organizadas, que, mais adiante, aparecem personificados na imagem das autoridades, conforme retomarei. "Inimigos" que ocultariam "que o real problema do futebol vai além das torcidas”. Notemos, aqui, o uso de uma linguagem realista. Quando falamos em "real problema", assumimos que há problemas falsos, ilusórios. E, implicitamente, que há uma consciência falsa e uma verdadeira, sendo que esta última teria acesso ao mundo tal como ele de fato é. Essa linguagem realista serve de base para a ideia de alienação. De que os torcedores organizados teriam se "libertado" do mundo imediato, abstrato, da aparência, para chegar ao concreto. Este seria alcançado por todos por meio de muita "conversa e diálogo". O diálogo seria, portanto, o instrumento capaz de trazer a "luz" às pessoas. Impossível não notar, aqui, o ressoar da obra platônica. Ainda que muito pouco lida efetivamente, tal obra parece orientar o pensamento ocidental até hoje, fazendo-se presente no nosso dia-a-dia e manifestando-se nas mais diversas formas simbólicas, como um manifesto de torcida organizada.

O que é engraçado nessa história toda é que quando há promoção de ingressos, os estádios enchem e por um momento a violência no futebol deixa de existir. Isso já abre ao menos um ponto para reflexão. Pensando em tudo isso da forma que somos usados e marginalizados, nós os torcedores organizados acordamos e entendemos que o que muitos não queriam agora vai acontecer. Tenham medo sim, pois vamos mostrar que o real problema do futebol vai além das torcidas. Com muita conversa e dialogo vamos fazer isso juntos.

Em seguida, o manifesto esclarece que a Anatorg não promete o fim das brigas e das mortes (o que a protege de futuras cobranças), pois isso seria papel do Estado também. Aqui, é interessante observar o uso do advérbio "também”, que indica inclusão. As organizadas possuiriam, assim, responsabilidade na prevenção da violência, embora esta não devesse ser apenas delas, como o manifesto esclarece em seguida. A fim de legitimar seu argumento, o de que responsabilidade pela prevenção da violência deve ser dividido com o Estado, o manifesto sustenta que a ausência de segurança pública e educação (que são de responsabilidade do Estado) afeta o dia-a-dia das organizadas. Logo em seguida, promete que a Anatorg irá trabalhar para solucionar o problema.

Não prometemos o fim das brigas e das mortes, pois isso é um serviço do Estado também - e não apenas nosso -, já que segurança pública e educação 
são coisas raras e que afetam o nosso segmento e não somos nós que vamos erradicar tal problema nas torcidas organizadas. Porém, vamos trabalhar e articular sim com a responsabilidade a nós exercida, na tentativa da diminuição de tais problemas.

Depois, o manifesto afirma que as autoridades buscam segmentar as torcidas organizadas. Mais do que uma afirmação, trata-se de uma acusação. Uma acusação que, implicitamente, posiciona as autoridades como "inimigas" de tais torcidas. Essa tentativa, todavia, não seria suficiente para "pará-las", pois a Anatorg teria sido fundada justamente para trabalhar a seu favor, já que teriam sido "abandonadas" pelo governo e sociedade. Por fim, o manifesto funde a voz da Anatorg com a do movimento ultra alemão, fazendo do lema do último o seu e convocando os demais atores ao diálogo.

Às autoridades que induzem as nossas brigas para que não aja a interlocução entre as torcidas dizemos que isso não será o suficiente para nos parar. E é com orgulho que informamos oficialmente que fundamos no dia 13/12/2014 a ASSOCIAÇÃO NACIONAL DAS TORCIDAS ORGANIZADAS com o intuito de trabalhar em prol desse segmento abandonado pelos governantes e pela sociedade Brasileira. Seguindo um conceito do movimento ultras que vem da Alemanha fica aqui o nosso recado: "FALE CONOSCO E NÃO SOBRE NÓS”!

\section{DISCUSSÃO}

Os resultados das análises apresentadas no tópico anterior reforçam as críticas feitas, desde os anos 1980, de que o futebol não deve ser interpretado como mero "ópio do povo", como se ele contribuísse, necessariamente, para integrar os indivíduos na ordem social capitalista que os explora. Definitivamente, o torcedor não é uma esponja que absorve indiscriminadamente as mensagens veiculadas pela indústria do futebol. Ele é capaz de (res)significá-las e contestá-las. Isso não significa, todavia, que ele seja capaz de fazer isso ao seu bel prazer. Kellner (2011), em seu estudo sobre a cultura da mídia, já alertava para os perigos de louvar a resistência per se, sem fazer distinção entre suas diferentes formas. Por exemplo, o fato de alguns grupos de torcedores confrontarem a polícia não significa, necessariamente, que coloquem em xeque as estruturas de dominação da sociedade. Afinal, a violência pode ser vista como uma forma extrema de expressão de uma "masculinidade agressiva”.

Para uma ação ser caracterizada como uma prática de resistência ela deve, portanto, fazer frente às assimetrias permanentes, que resultam em desigualdades e injustiças sociais. $\mathrm{E}$ 
fazer isso, no caso das torcidas de futebol, pode envolver tanto ações sem organização formal e feitas de forma individual - como quando um indivíduo se recusa a assistir a uma partida sentando, afrontando um modelo burguês de torcer, que propõe uma relação distanciada com o espetáculo futebolístico (LOPES; HOLLANDA, 2018b) - quanto ações feitas de forma coletiva e organizada, como são os casos da fundação de movimentos e associações, como o AGIR e a Anatorg.

No caso do AGIR, seu manifesto de fundação coloca em xeque uma série de formas de dominação que, com frequência, estão tão cristalizadas no universo do futebol que sequer são percebidas, permanecendo na penumbra. Por exemplo, ao adotar uma linguagem inclusiva do ponto de vista de gênero, o AGIR constrói a si mesmo como um movimento tolerante, que abriga a diversidade. Essa construção identitária é, como qualquer outra, uma prática, que, no caso, contribui para afrontar o sexismo e a homofobia estruturante do referido universo. Tratase, nesse sentido, de uma identidade de resistência, ou seja, de um discurso sobre si que desafia a ordem social vigente.

No caso da Anatorg, seu manifesto de fundação coloca em xeque a narrativa hegemônica sobre as torcidas organizadas. Narrativa que estigmatiza os membros dessas torcidas, fundindo-os com a figura do torcedor violento. O torcedor organizado é, com muita frequência, construído como o protagonista das cenas de barbárie que ocorrem dentro e fora dos estádios de futebol. Cenas que costumam chamar a atenção dos meios de comunicação, impactar a opinião pública e mobilizar as autoridades públicas (LOPES, 2019). A fim de refutar essa narrativa, o manifesto emprega uma complexa estratégia de construção identitária: evoca as ideias-feitas das organizadas para construí-las como a negação dessas ideias. A identidade dessas torcidas é, nesse sentido, uma resposta à referida narrativa.

Nessa resposta, é importante observar o uso feito de determinados argumentos que, de modo descontextualizado, poderiam ser lidos apenas como conservadores, no sentido de estarem, necessariamente, a serviço da ordem social dominante. Por exemplo, a ideia de que a sociedade é manipulada pelos meios de comunicação posiciona a população em uma posição de passividade, ocultando seu potencial crítico e transformador. No entanto, no manifesto, essa ideia serve de base para atacar o processo de estigmatização das organizadas, que tende a mantê-las em uma posição subalterna no debate público sobre o futebol, já que não seriam fontes confiáveis de informação e reflexão (LOPES, 2019). Nesse sentido, considero que o instrumental teórico-metodológico adotado foi particularmente vantajoso, uma vez que, se me debruçasse sobre as ideias em si e não sobre aquilo que efetivamente fazem em um contexto 
concreto (legitimando, problematizando, negando, desautorizando... determinadas práticas discursivas ou não), perderia de vista seu potencial contestatório.

Em comum, podemos dizer que ambos os manifestos convocam agrupamentos (coletivos de esquerda, no caso do AGIR, e torcidas organizadas, no caso da Anatorg) para se unirem, independentemente das diferenças e divisões que possam separá-los. Ao mesmo tempo em que serve para criar uma identidade coletiva, essa convocação contribui para minar uma das principais estratégias utilizadas pelas forças dominantes do futebol e da sociedade em geral para incapacitar grupos subalternos de se transformarem em um desafio real a elas: a fragmentação. Afinal, a divisão, como a história já demonstrou em diversas ocasiões, pode servir para desarticular. Para desmobilizar. Para subjugar, em suma.

\section{CONSIDERAÇÕES FINAIS}

Neste artigo, discuti como o AGIR e a Anatorg constroem suas identidades em seus manifestos de fundação e de que maneiras configuram as lutas políticas no futebol. Ao fazer isso, busquei mostrar que essas identidades são respostas a determinados fenômenos sociais, como a ascensão da extrema direita ao poder e a estigmatização das torcidas organizadas. Também busquei mostrar que elas podem ser caracterizadas como formas de crítica a relações de opressão e dominação presentes tanto no universo do futebol quanto na sociedade em geral, como as de gênero. Em trabalhos futuros, pretendo verificar como tais identidades estimulam, facilitam, permitem ou interditam determinadas práticas sociais no cotidiano desses agrupamentos, influenciando suas formas de organização e seus modos de operação.

\section{REFERÊNCIAS}

BEST, Joel. Audiences evaluate statistics. In: BEST, Joel.; LOSEKE, Donileen. R. (Ed.). Social problems: constructionist readings. New York: Walter de Gruyter, 2003. p. 43-50.

BRUGNAGO, Fabrício; CHAIA, Vera. A nova polarização política nas eleições de 2014: radicalização ideológica da direita no mundo contemporâneo do Facebook. Aurora: revista de arte, mídia e política. v.7, n.21, 2014-2015, p. 99-129.

ECO, Umberto. Apocalípticos e integrados. São Paulo: Perspectiva, 1979.

FAIRCLOUGH, Norman. Discurso e mudança social. Brasília: EdUNB, 2008.

GERGEN, Kenneth J.; GERGEN, Mary. Reflexiones sobre la construcción social. Barcelona, Paidós, 2011. 
GIULIANOTTI, Richard. Sociologia do futebol: dimensões históricas e socioculturais do esporte das multidões. São Paulo: Nova Alexandria, 2002.

IBÁÑEZ, Tomás. Municiones para disidentes: realidad-verdad-política. Barcelona: Gedisa, 2001.

O giro linguístico. In: IÑIGUEZ, Lupicinio (Coord.). Manual de Análise do Discurso em Ciências Sociais. Petrópolis, Editora Vozes, 2004, p. 19-49.

Contra la dominación: variaciones sobre la salvaje exigencia de libertad que brota del relativismo y dTe las consonancias entre Castoriadis, Foucault, Rorty e Serres. Barcelona: Gedisa, 2005.

IÑIGUEZ, Lupicinio. Construcionismo social. In: MARTINS, João Batista; EL HAMMOUTI, Nour-Din El Hammouti; IÑIGUEZ, Lupicinio (Orgs.). Temas em análise institucional e em construcionismo social. São Carlos: Rima, 2002, p. 99-180.

. Identidad: De lo Personal a lo Social. Un Recorrido Conceptual. IN: CRESPO, Eduardo (Ed.). La constitución social de la subjetividad. Madrid: Catarata, 2001, p. 209225.

LOPES, Felipe Tavares Paes. Violência: ideologia na construção de um problema social. Curitiba: CRV, 2019.

LOPES, Felipe Tavares Paes; HOLLANDA, Bernardo Buarque de. 'Futebol moderno': ideologia, sentidos e disputas na apropriação de uma categoria futebolística. Revista de Estudios Brasileños, v. 5, 2018a, p. 159-175.

. "Ódio eterno ao futebol moderno": poder, dominação e resistência nas arquibancadas dos estádios da cidade de São Paulo. Movimento. v. 24, n. 2, 2018b, p. 207-232. LÖWY, Michael. Conservadorismo e extrema-direita na Europa e Brasil. Serviço Social \& Sociedade. n. 24, 2015, p. 652-664.

KELLNER, Douglas. A cultura da mídia. Estudos culturais; identidade e política entre o moderno e o pós-moderno. Bauru: EDUSC, 2001.

MASCARENHAS, Gilmar. Entradas e bandeiras: a conquista do futebol pelo Brasil. Rio de Janeiro, 2014.

NACIF, Cristina Lontra; FAULHABER, Lucas. Desapropriações e remoções para tornar o Rio de Janeiro competitivo. In: SANCHEZ, Fernanda et al. (Org.). A Copa do Mundo e as cidades: políticas, projetos e resistências. Niterói: Editora da UFF, 2014, p. 139-160.

NUMERATO, Dino. Who says "no to modern football?" Italian supporters, reflexivity, and neo-liberalism. Journal of Sport and Social Issues, 2014, p. 1-19.

OLIVEIRA, Nelma Gusmão; VAINER, Carlos. Megaeventos no Brasil e no Rio de Janeiro: uma articulação transescalar na produção da cidade de exceção. In: SANCHEZ, Fernanda et 
al. (Org.). A Copa do Mundo e as cidades: políticas, projetos e resistências. Niterói: Editora da UFF, 2014, p. 81-118.

POTTER, Jonathan. La representación de la realidad: discurso, retórica y construcción social. Barcelona: Paidós, 1998.

ROJO, Luisa Martí. A frontera interior - análise crítica do discurso: um exemplo sobre o "racismo". In: IÑIGUEZ, Lupicinio (Coord.). Manual de Análise do Discurso em Ciências Sociais. Petrópolis, Editora Vozes, 2004, p. 206-257.

SPINK, Mary Jane; FREAZZA, Rose Mary. Práticas Discursivas e produção de sentidos: a perspectiva da Psicologia Social. In: SPINK, Mary Jane. (Org.). Práticas Discursivas e produção de sentidos no cotidiano: aproximações teóricas e metodológicas. São Paulo: Cortez, 1999, p. 17-40.

SANTOS, Irlan Simões da Cruz. Clientes versus rebeldes: novas culturas torcedoras nas arenas do futebol moderno. Rio de Janeiro: Multifoco, 2017.

. Mercantilização do futebol e movimentos de resistência dos torcedores: histórico, abordagens e experiências brasileiras. Esporte e Sociedade, n. 27, p. 1-18, 2016.

SANTOS, Irlan Simões da Cruz; HELAL, Ronaldo. Do espectador ao militante: a torcida de futebol e a luta pelo direito ao estádio e ao clube. Tríade: Revista de Comunicação, Cultura e Mídia, v. 3, n. 7, p. 54-69, 2016.

TEIXEIRA, Rosana; LOPES, Felipe Tavares Paes. Reflexões sobre o "Projeto Torcedor" alemão: produzindo subsídios para o debate acerca da prevenção da violência no futebol brasileiro a partir de uma perspectiva sociopedagógica. Revista Antropologia, v. 61, n. 13, 2018, p. 130-161.

\section{Original recebido em: 15 de outubro de 2019}

Aceito para publicação em: 01 de maio de 2020

Felipe Tavares Paes Lopes

Doutor em Psicologia Social pelo IP-USP. Realizou pesquisas de pós-doutorado na FEFUnicamp e no CPDOC-FGV. Atualmente, é docente Programa de Pós-Graduação em Comunicação e Cultura da UNISO e possui auxílio pesquisa da Fapesp.

\section{(2) $\odot \Theta(0)$}

Esta obra está licenciada com uma Licença

Creative Commons Atribuição-NãoComercial-CompartilhaIgual 4.0 Internacional 